\title{
Proposal of a questionnaire to investigate social communication skills of children with typical development and communication disorders
}

Shelly Lagus ${ }^{1}$ https://orcid.org/0000-0002-1138-1035

Fernanda Dreux Miranda Fernandes ${ }^{1}$ https://orcid.org/0000-0002-3382-9427

Universidade de São Paulo, Faculdade de Medicina, Departamento de Fonoaudiologia, Fisioterapia e Terapia Ocupacional, São Paulo, São Paulo, Brasil.

Research support source: Fundação de Amparo à Pesquisa do Estado de São Paulo (2017/25704 -1).

Conflict of interests: Nonexistent

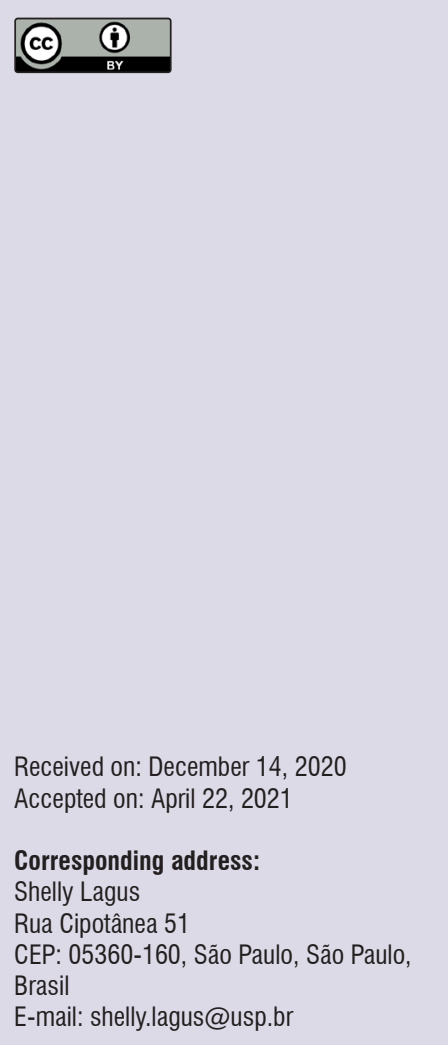

\section{ABSTRACT}

Purpose: to verify the possibility of administering a simple questionnaire to family members who communicate with their children to identify communication functional characteristics of children with different manifestations of language development.

Methods: 95 parents/guardians were individually interviewed. Their children were afterwards diagnosed with language disorder (LD), speech production disorder (SPD), autism spectrum disorder (ASD), and typical development (TD). The interviews were conducted with the Communicative Skills Questionnaire to characterize the pragmatic performance. The Student's t-test and the principal component analysis were used in statistical analysis, considering significant p-values $<0.05$.

Results: the statistical analyses reveal that the questionnaire distinguished the groups of children diagnosed with autism spectrum disorder and language disorder from the groups of children with speech production disorders and typical development.

Conclusion: the questionnaire proved to be capable of distinguishing and characterizing, from the pragmatic standpoint, the children with different manifestations of communication development, revealing the impaired pragmatic skills of children with autism spectrum disorders and language disorders.

Keywords: Speech, Language and Hearing Sciences; Language; Child; Social Communication 


\section{INTRODUCTION}

Language is a system of rules and principles that enable interlocutors to code meanings into sounds while listeners decode their meanings ${ }^{1}$. On the other hand, language is also endlessly creative, allowing the interlocutor and listener to create, understand, and modify an infinite set of new utterances. Language is an instrument for communication and thought development ${ }^{1,2}$.

Pragmatics reveal how linguistic and nonlinguistic skills are used to communicate ${ }^{1}$. They result from the interaction between individual linguistic, cognitive, and sensory processes and the manner how one interacts with others, encompassing the formal aspects that define the adjustments and variations motivated by the communication context, which in turn implies in the use of language in relation to the characteristics of both the interlocutor and the situation ${ }^{2-6}$.

The study of pragmatics relates the phonological, semantic, and syntactic aspects of language to the context in which it takes place, approaching its different uses $^{2,3}$. If such a context is known, the topic can be communicated without necessarily verbalizing the person's intention ${ }^{4}$.

In typical language development, pragmatic skills appear at an early age. Even before uttering words, the child can respond nonverbally to other people's social initiatives. As language develops, the interaction is improved, making the child increasingly more active in communication, using more interactive communicative functions ${ }^{2-4}$.

In some cases, pragmatic skills are not typically acquired. A break or failure in the intentional nature of communication is the main characteristic observed in pragmatic disorders. The changes in this linguistic aspect manifest as difficulties to correctly interpret other people's actions and/or properly express their desires and intentions ${ }^{2-8}$.

Recent research concluded that language acquisition and development are essential to the child's life, especially because it enables their socialization with the world. A child with language difficulties can have many personal/social consequences, making it harder for them to interact with their surroundings ${ }^{2,4}$.

Socialization requires effective communication skills $^{2-9}$, encompassing nonverbal communication and facial expression comprehension - which is essential to social behavior ${ }^{3,10}$.

An instrument that verifies the functional characteristics of communication of children with different speech and language disorders and identifies specific characteristics related to the various conditions can efficiently help the diagnostic process and the referral to adequate services and intervention processes.

This study aimed to verify the possibility of administering a simple questionnaire to family members who communicate with their children, to initially identify the functional characteristics of communication of children with different manifestations of language development.

\section{METHODS}

This research was submitted to the Ethics Committee of the Faculdade de Medicina da Universidade de São Paulo - FMUSP (Medical School at the University of São Paulo), Brazil, and approved under protocol number 1818136. The participants were included in the research only after one of their parents/guardians had signed the informed consent form.

The instrument is intended to map pragmatic skills performance as communication initiative, communication interactivity, means of communication used, functional diversity, discourse skills, and socio-communicative adaptation of children with language disorders. The questions that make up the questionnaire were based on existing protocols, particularly the Functional Communication Profile ${ }^{10,11}$ and Autism Behavior Checklist ${ }^{12}$.

To achieve its goal, the questionnaire was adapted after being administered in a pilot study ${ }^{11}$, aiming at further detailing communicative characteristics. Hence, the questionnaire (Annex 1 ) comprises 30 questions.

The questionnaire was formally structured for this study with a Likert-type scale, which gave the interlocutors the following options from which to choose: "Never", "Sometimes", "Frequently", and "Almost always".

The groups in the study were organized according to the American Speech-Language-Hearing Association $(1993)^{14}$, which divides the communication disorders into impairments in the ability to receive and/or process a symbol system, language (form, content, and communicative function), and speech processes (articulation, voice, and fluency). Besides these, a group of children with autism spectrum disorder (ASD) was recruited, due to their primary deficit in pragmatic skills.

Criteria were established to include participants and verify the applicability of the questionnaire and its usefulness in characterizing pragmatic performance. They were as follows: children aged 2 to 12 years, with diagnostic hypothesis of language disorder 
(LD), speech production disorder (SPD), ASD, or typical development (TD). The exclusion criteria were incomplete data, refusal to participate, and diagnosis of moderate to profound hearing loss or multiple deficiencies. The parents/guardians of the 95 children were individually interviewed and the participants were divided into four groups:

- TD group - Parents/guardians of 45 children with no speech-language-hearing complaints, attending regular school, mean age 4 years and 9 months.

- ASD group - Parents/guardians of 28 children with clinical diagnosis included within the autism spectrum disorder, undergoing speech-language-hearing therapy at the Laboratory for SpeechLanguage-Hearing Investigation of the Autism Spectrum Disorders (LIF - DEA, in Portuguese) of the Speech-Language-Hearing Sciences program at USP medical school. Their mean age was 4 years and 8 months.

- LD group - Parents/guardians of 14 children with communication disorders related to language processing, attended by the speech-language-hearing screening service of the Speech-LanguageHearing Sciences program at USP medical school. Their mean age was 6 years and 5 months.
- SPD group - Parents/guardians of 8 children with communication disorders related to speech production, attended by the speech-language-hearing screening service of the Speech-LanguageHearing Sciences program at USP medical school. Their mean age was 6 years and 10 months.

These subjects were recruited to identify the communicative skills in the different manifestations of communication development.

The statistical analysis was conducted with Student's t-test and principal component analysis, considering significant $\mathrm{p}$-values $<0.05$.

\section{RESULTS}

A total of 95 parents/guardians were interviewed, whose children's mean age was 5 years and 2 months. The statistical analysis performed with Student's t-test revealed no statistical difference between the sexes in the groups studied.

The participants were divided into four groups, as shown in Figure 1: TD with 45 (47.36\%) participants, mean age 4 years and 9 months; ASD with 28 (29.47\%) children, mean age 4 years and 8 months; LD with 14 $(15.78 \%)$ subjects, mean age 6 years and 5 months; and SPD with 8 (7.39\%) children, mean age 6 years and 10 months.

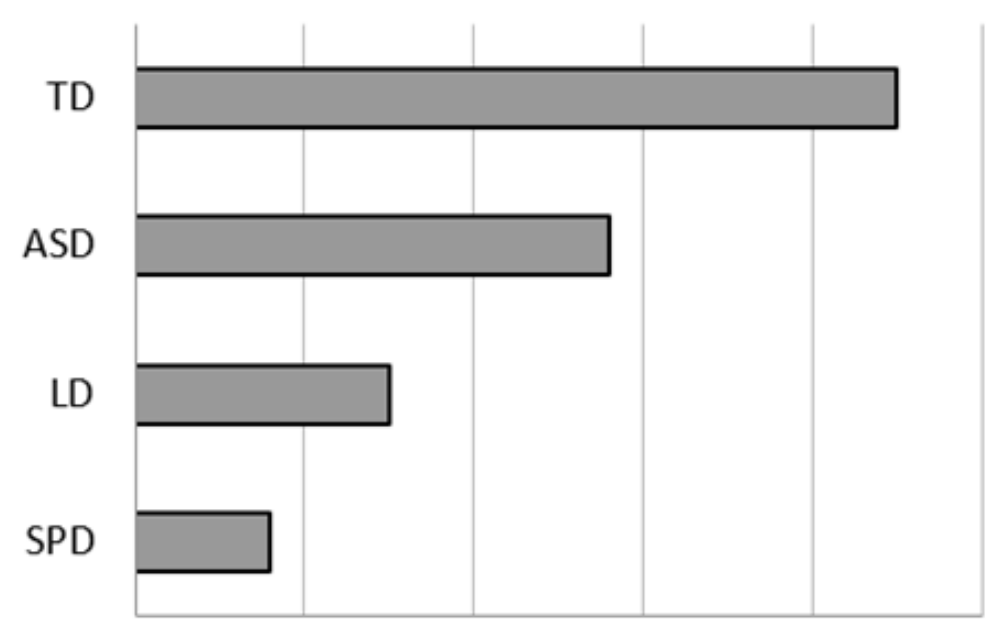

\section{$\begin{array}{llllll}0.00 \% & 10.00 \% & 20.00 \% & 30.00 \% & 40.00 \% & 50.00\end{array}$}

Captions: $\mathrm{TD}=$ typical development; $\mathrm{LD}=$ language disorder; $\mathrm{SPD}=$ speech production disorder; $\mathrm{ASD}=$ autism spectrum disorder

Figure 1. Sample characterization 
The main component analysis of the answers regarding the study group, as observed in Figure 2, identified the quantitative relevance of groups with diagnostic hypotheses of LD, ASD, and SPD (such as fluency disorders and oral-motor function, with much smaller numbers). The most relevant questions to distinguish these groups were identified as numbers 1, 2, 4, $7,8,11,12,19,20,24,26$, and 29. Both the questions and the groups they distinguish are described in Chart 1.

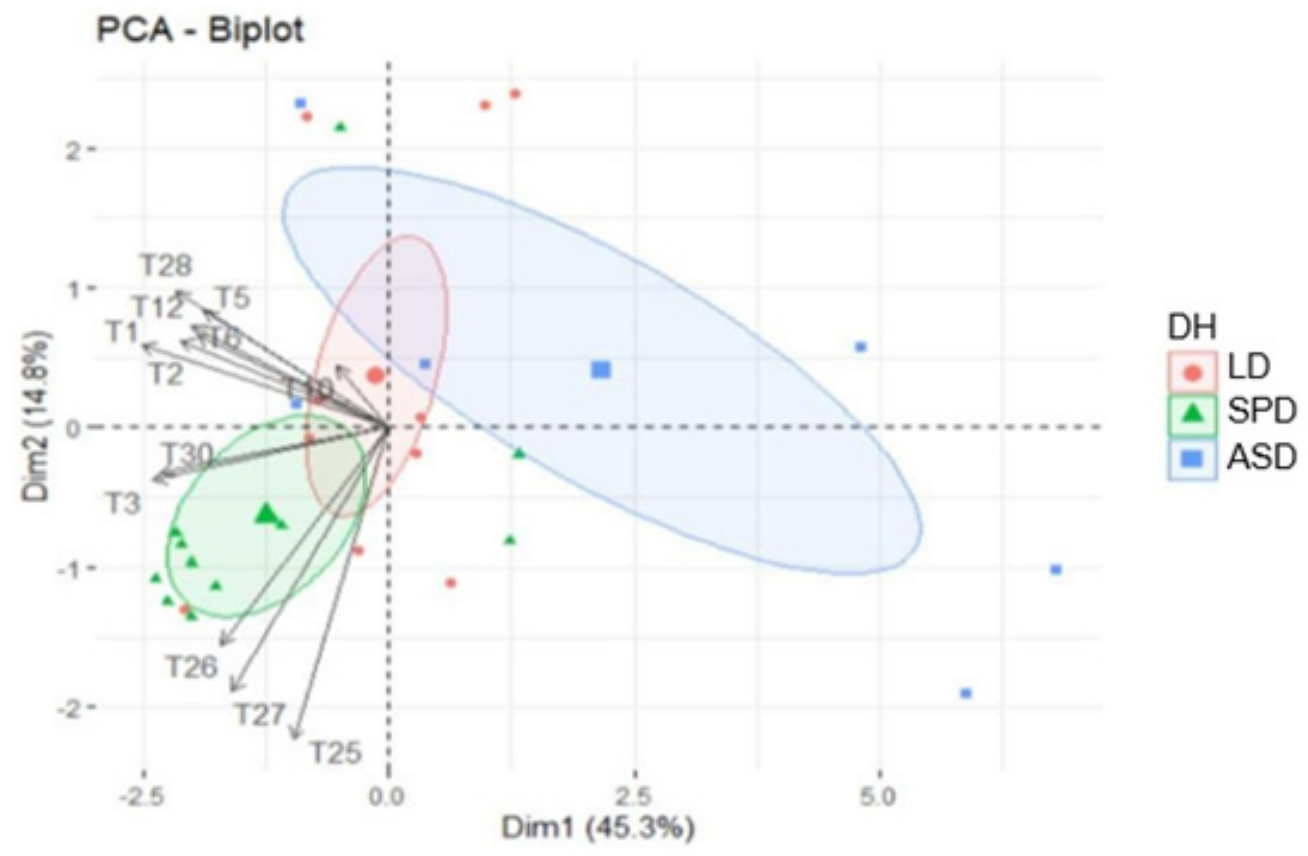

Captions: PCA = Principal Component Analysis; Dim = Dimension; $T$ = Mean of the parents'/guardians' answers; $\mathrm{DH}=$ diagnostic hypothesis; $\mathrm{LD}=$ language disorder; SPD = speech production disorder; ASD = autism spectrum disorder

Figure 2. Principal component analysis of the answers regarding the subjects with autism spectrum disorder, language disorder, and speech production disorder

Chart 1. Questions identified as the most relevant to distinguish the groups

\begin{tabular}{|c|l|c|}
\hline \multicolumn{1}{|c|}{ Question } & Similarity between groups \\
\hline 1 & Does the child interact with their parents/caregivers? & ASD $\neq$ LD/SPD/TD \\
\hline 2 & Does the child interact with other adults or older children? & ASD $\neq \mathrm{LD} \neq \mathrm{SPD} / \mathrm{TD}$ \\
\hline 4 & Does the child look at their parents when called? & $\mathrm{ASD} \neq \mathrm{LD} / \mathrm{SPD} / \mathrm{TD}$ \\
\hline 7 & Does the child make repetitive movements? & $\mathrm{ASD} \neq \mathrm{LD} / \mathrm{SPD} / \mathrm{TD}$ \\
\hline 8 & Does the child make repetitive movements when stressed? & $\mathrm{ASD} \neq \mathrm{LD} / \mathrm{SPD} / \mathrm{TD}$ \\
\hline 11 & Does the child thank or greet? & $\mathrm{ASD} \neq \mathrm{LD} \neq \mathrm{SPD} / \mathrm{TD}$ \\
\hline 12 & Does the child express liking or disliking anything? & $\mathrm{ASD} / \mathrm{LD} \neq \mathrm{SPD} / \mathrm{TD}$ \\
\hline 19 & Does the child accept hugs, physical contact? & $\mathrm{ASD} \neq \mathrm{LD} / \mathrm{SPD} / \mathrm{TD}$ \\
\hline 20 & Is the child excessively interested in anything? & $\mathrm{ASD} / \mathrm{LD} \neq \mathrm{SPD} / \mathrm{TD}$ \\
\hline 24 & Does the child make friends? & $\mathrm{ASD} / \mathrm{LD} \neq \mathrm{SPD} / \mathrm{TD}$ \\
\hline 26 & Does the child understand/obey orders? & $\mathrm{ASD} \neq \mathrm{LD} / \mathrm{SPD} / \mathrm{TD}$ \\
\hline 29 & Does the child call the objects and images by their names? & $\mathrm{ASD} / \mathrm{LD} \neq \mathrm{SPD} / \mathrm{TD}$ \\
\hline
\end{tabular}

Captions: TD = typical development; LD = language disorder; SPD = speech production disorder; ASD = autism spectrum disorder 
The principal component analysis (Figure 2) demonstrates the possibility of using the results of the questionnaire to identify children with conditions compatible with the autism spectrum, besides pointing out that the subjects with LD have communicative behaviors more similar to that of children with ASD than those with SPD.

Of the 30 questions, 11 were highly sensitive to distinguish children with ASD from any of the other three groups. Also, in most of the questions, the parents used the extremes of the scale, demonstrating more rigid communicative behaviors.

The parents/guardians of children with ASD and LD indicated similar pragmatic behaviors between the two groups in nine questions. The groups of children with SPD and TD were also similar in these same questions, although differing from the other two groups.

In seven questions, there were no differences between children with TD and SPD, although the groups of children with ASD and LD were different from each other and the TD and SPD groups.

Two questions were similar between the groups of children with ASD and SPD, while only one question differed in all the groups.

\section{DISCUSSION}

The questions "Does the child interact with their parents/caregivers?", "Does the child interact with other adults or older children?", and "Does the child look at their parents when called?" had a high differentiation index between the ASD children and the other groups. These three questions approach social aspects such as friendship and social interaction, which usually distinguish children with ASD from those with other communication disorders ${ }^{8,13-16}$.

The questions "Does the child make repetitive movements?" and "Does the child make repetitive movements when stressed?" differed all the groups. However, most of their affirmative answers refer to the children in the ASD group. In the literature, these behaviors are characteristic of ASD and are used as diagnostic criteria for the disorder ${ }^{14,15}$. One aspect to consider when interpreting this finding is the age difference between the ASD children and those with the other language development manifestations ${ }^{2}$, as children whose development is not included within the autism spectrum make important progress in their form of expression ${ }^{4,5,5,9,13,17-19}$.

The question "Does the child thank or greet?" distinguishes the group of children with ASD from the groups with LD, SPD, and TD ${ }^{16,17}$. Children with ASD and LD had the expected discourse deficits, due to the linguistic issues that permeate such disorders $8,19,20$. This question approaches the discourse skills, pointing to the study by Sawasaki $(2018)^{6}$, in which the children with specific language disorder had more inadequate answers than those with TD - especially in the more complex elaborations and in the answer structure skills. The authors consider that this happens because such skills need further discourse development.

The question "Does the child make friends?" deals with pragmatic and social skills and joins children with ASD and LD. Such a finding was also observed in international research, such as that by Bishop, Havdahl, and Huerta $(2016)^{4}$, and Helland and Helland $(2017)^{8}$. Both studies conclude that the pragmatic difficulty, with different causes in each group, generates emotional and behavioral issues that influence their social skills to develop a relationship with their developmental peers.

The questions "Does the child express liking or disliking anything?", "Is the child excessively interested in anything?", and "Does the child call the objects and images by name?" joined the children with ASD and LD. This is an interesting fact that agrees with the literature, as these children have language deficits that restrict the semantic fields, due to either linguistic difficulties or secondary issues, as in children with ASD ${ }^{4-7,15}$.

The questions "Does the child accept hugs, physical contact?" and "Does the child understand/obey orders?" differ the ASD group from the other ones, which agrees with the most up-to-date literature ${ }^{4-8,16}$. The qualitative analysis of the answers presents an interesting datum: These questions also divide the parents/guardians of autistic children because most of them gave heterogeneous answers. Heterogeneity in children within this spectrum has been reported by researchers such as Bishop, Havdahl, and Huerta $(2016)^{4}$, and Helland and Helland (2017) ${ }^{8}$.

Most of the questions revealed similarities between the groups of children with TD and SPD. This finding can be explained by the few subjects in the SPD group and by the social communication characteristics of the children with SPD. These children have discourse deficits due to their difficulty in producing speech, different from children with cognitive-linguistic disorders.

\section{CONCLUSION}

The study concluded that children with communication disorders have deficits in pragmatic skills 
when compared with those with typical development. However, among the children with communication disorders, the group closest to TD is that of children with SPD, whereas those with ASD and LD are near each other because they are different manifestations of communication development. Moreover, children with ASD have a significant deficit in social communication pragmatic skills, due to the characteristics related to this diagnosis.

The questionnaire proposed proved to be capable of distinguishing and characterizing, from the pragmatic standpoint, the children with different manifestations of communication development, especially those with ASD and LD, which are specific language disorders. However, further research is necessary, with larger participating groups, to verify the possibility of outlining specific characteristics of each one of the different groups.

\section{ACKNOWLEDGMENTS}

Gratitude is extended to the Fundação de Amparo à Pesquisa do Estado de São Paulo (2017/25704 -1)

\section{REFERENCES}

1. Yamashiro A, Vouloumanos A. Are linguistic and social-pragmatic abilities separable in neurotypical infants and infants later diagnosed with ASD? Dev Psychol. 2019;55(5):920-33.

2. Topal Z, Demir Samurcu N, Taskiran S, Tufan $A E$, Semerci B. Social communication disorder: a narrative review on current insights. Neuropsychiatr Dis Treat. 2018;14:2039-46.

3. Ochs-Keenan E. Conversational competence in children. In: Ochs-Keenan E, Schieffelin B, editors. Acquiring conversational competence. London: Routledge \& Kegan Paul, 1983. p. 3-25.

4. Bishop SL, Havdahl KA, Huerta M. Subdimensions of social $\square$ communication impairment in autism spectrum disorder. J Child Psychol Psychiatry. 2016;57(8):909-16.

5. Zheng S, Kaat A, Farmer C, Kanne S, Georgiades $\mathrm{S}$, Lord $\mathrm{C}$ et al. Extracting latent subdimensions of social communication: a cross-measure factor analysis. J Am Acad Child Adolesc Psychiatry. 2020;S0890-8567(20)31952-3.
6. Sawasaki LY. Identificação pragmática da linguagem e comunicação social: estudo comparativo entre crianças com transtornos de comunicação [Dissertation]. Bauru (SP): Universidade de São Paulo, Faculdade de Odontologia de Bauru; 2018.

7. Thapar A, Cooper M, Rutter M. Neurodevelopmental disorders. Lancet Psychiatry. 2017;4(4):339-46.

8. Helland WA, Helland TI. Emotional and behavioural needs in children with specific language impairment and in children with autism spectrum disorder: The importance of pragmatic language impairment. Res Dev Disabil. 2017;70:33-9.

9. Vissers C, Koolen S. Theory of mind deficits and social emotional functioning in preschoolers with specific language impairment. Front Psychol. 2016;7:1734.

10. Andrade CR, Befi-Lopes DM, Fernandes FD, Wertzner HF. ABFW- Teste de linguagem infantil nas áreas de fonologia, vocabulário, fluência e pragmática. Carapicuíba: PróFono; 2000.

11. Neubauer MA, Fernandes FD. Functional communication profile and speech-language diagnosis in children of the autism spectrum: checklist use. CoDAS. 2013;25(6):605-9.

12. Krug D, Arick J, Almond P. Autism Behavior Checklist - ABC. In: Krug DA, Arick J, Almond $P$, editors. Autism Screening Instrument for Educational Planning- ASIEP-2. Austin, Texas: PRO-ED; 1993. p. 37-58.

13. Lagus S, Fernandes FDM. Investigação das habilidades comunicativas de crianças com desenvolvimento típico e com autismo. In: Castro LHA, Pereira TT, Moreto FVC, editors. Propostas, Recursos e Resultados nas Ciências da Saúde 8. Ponta Grossa: Atena Editora; 2020. p. 72-80.

14. ASHA: American Speech-Language-Hearing Association. Definitions of communication disorders and variations. 1993. [cited 2020 Dec14]. Available from: www.asha.org/policy

15. American Psychiatry Association. Diagnostic and Statistical Manual of Mental disorders - DSM-5. 5th. ed. Washington: American Psychiatric Association, 2013.

16. Parmeggiani A, Corinaldesi A, Posar A. Early features of autism spectrum disorder: a crosssectional study. Ital J Pediatr. 2019;45:144. 
17. Simoni SN, Leidow IC, Britz DL, Moraes DAO, Keske-Soares M. Impact of the speech sound disorders: family and child perception. Rev. CEFAC. 2019;21(3):e10718.

18. Shriberg LD, Strand EA, Jakielski KJ, Mabie $\mathrm{HL}$. Estimates of the prevalence of speech and motor speech disorders in persons with complex neurodevelopmental disorders. Clin Linguist Phon. 2019;33(8):707-36.

19. Burnside K, Wright K, Poulin-Dubois D. Social motivation and implicit theory of mind in children with autism spectrum disorder. Autism Res. 2017;10(11):1834-44.

20. Rodrigues VA, Santana GMR, Expósito SH. Executive functions and language in children with different subtypes of specific language impairment. Neurologia. 2017;32(6):355-62. 


\section{ANNEX 1}

\section{Communicative Skills Questionnaire}

\begin{tabular}{|c|c|c|c|c|c|}
\hline \multicolumn{2}{|r|}{ QUESTIONS } & \multirow[t]{2}{*}{ Never } & \multirow[t]{2}{*}{ Sometimes } & \multirow[t]{2}{*}{ Frequently } & \multirow[t]{2}{*}{$\begin{array}{l}\text { Almost } \\
\text { always }\end{array}$} \\
\hline 1 & Does the child interact with their parents/caregivers? & & & & \\
\hline 2 & Does the child interact with other adults or older children? & & & & \\
\hline 3 & Does the child play with other children their age? & & & & \\
\hline 4 & Does the child look at their parents when called? & & & & \\
\hline 5 & Does the child look at their parents when they are talking? & & & & \\
\hline 6 & Does the child start conversations/plays? & & & & \\
\hline 7 & Does the child make repetitive movements? & & & & \\
\hline 8 & Does the child make repetitive movements when stressed? & & & & \\
\hline 9 & Does the child repeat the sentences or phrases they hear? & & & & \\
\hline 10 & $\begin{array}{l}\text { When stressed, does the child scream, or repeat sentences or } \\
\text { phrases they hear? }\end{array}$ & & & & \\
\hline 11 & Does the child thank or greet? & & & & \\
\hline 12 & Does the child express liking or disliking anything? & & & & \\
\hline 13 & Can the child show why they are unhappy? & & & & \\
\hline 14 & Does the child play with many toys? & & & & \\
\hline 15 & $\begin{array}{l}\text { Does the child have any toy or object they are particularly fond of? } \\
\text { (e.g., one they look for when sad, stressed, or going to bed) }\end{array}$ & & & & \\
\hline 16 & Does the child ask for toys? & & & & \\
\hline 17 & Does the child play differently with the mother and the father? & & & & \\
\hline 18 & $\begin{array}{l}\text { Does the child play differently with people they know and do not } \\
\text { know? }\end{array}$ & & & & \\
\hline 19 & Does the child accept hugs, physical contact? & & & & \\
\hline 20 & Is the child excessively interested in anything? & & & & \\
\hline 21 & Does the child understand jokes? & & & & \\
\hline 22 & Does the child talk about their day at school? & & & & \\
\hline 23 & $\begin{array}{l}\text { Does the child react to environmental stimuli? (e.g., tickling, loud } \\
\text { noise) }\end{array}$ & & & & \\
\hline 24 & Does the child make friends? & & & & \\
\hline 25 & $\begin{array}{l}\text { Does the child participate in conversations, respecting the other } \\
\text { people's turn and talking in theirs? }\end{array}$ & & & & \\
\hline 26 & Does the child understand/obey orders? & & & & \\
\hline 27 & Does the child play make-believe? & & & & \\
\hline 28 & Do nonrelatives understand what the child says? & & & & \\
\hline 29 & Does the child call the objects and images by their names? & & & & \\
\hline 30 & Does the child refuse to participate in activities? & & & & \\
\hline
\end{tabular}

